\title{
Assessment of organizational and technological reliability of a construction organization during contract bidding
}

\author{
Elena Mikhaylova* \\ Moscow State University of Civil Engineering, 129377, Moscow, Russia
}

\begin{abstract}
In the current system of contract bidding, there are a number of problems, one of which is the imperfection of the evaluation criteria by which applicants are selected. The article presents a methodology for assessing the organizational and technological reliability of a construction organization and its competitive offers for tenders for construction and installation works. It is proposed to use the indicator of its organizational and technological reliability as a criterion for evaluating a construction organization that claims to fulfill a construction order. To determine the reliability of a construction company, information about the intensity of development of capital investments is used. This indicator allows you to assess how much the bidder can ensure the maximum return on the construction equipment and workers used, reduce the cost of construction using modern construction materials and resource-saving technologies. Each construction and installation organization will have its own intensity of development of capital investments. It depends on the qualification of employees, the availability and use of a fleet of construction machines and mechanisms, construction production technologies, construction organization methods, etc. As an indicator that characterizes the relative change in the actual development of capital investments from the standard or calculated value, the capital investment development index is used. Using retrospective data on the speed of capital investment development for similar objects or using variant design of the construction process, curves of accumulated probabilities of capital investment development indices are constructed, which are used to determine the organizational and technological reliability of the contract bidder. The proposed assessment of the reliability of a construction organization allows the customer (investor) to choose a reliable partner - contractor that best meets their requirements.
\end{abstract}

\section{Introduction}

At present, the key element of the state construction order implementation process is the contract system in the field of procurement of goods, works and services. Within the framework of contract bidding, the level of competitiveness of organizations of the construction complex that claim to win is evaluated. The creation of a system of

\footnotetext{
*Corresponding author: tranz-volga@yandex.ru
} 
competitions for placing state and municipal orders meant improving the quality of construction projects, stimulating competition and economic interaction in the construction contract market.

In practice, the current system of contract bidding demonstrates a number of problems that hinder the realization of its potential. One of the main reasons is the imperfection of the evaluation criteria used to select companies - applicants. When evaluating bids, customers traditionally focus on such competitive advantages as work experience, the use of advanced technologies in the implementation of construction and installation works, and the availability of qualified personnel. However, these indicators are no longer adequate to reality and do not show the reliability of the contractor in the construction services market.

As a criterion for evaluating a construction organization that claims to fulfill a construction order, it is proposed to use the indicator of its organizational and technological reliability.

The first definition of organizational and technological reliability was given by A. A. Gusakov [1]. By this term he understood the possibility of building a system designed to preserve quality in the conditions of disturbing factors. A.V. Ginzburg under the organizational and technological reliability understand the ability to achieve a given uncertainty in the external environment [2].

It should be noted that the concept of reliability is widely used in the study of socioeconomic, technical and production systems. If we omit the current concept of reliability in specific areas of human activity, such as medicine, then it is possible to limit the scope of this indicator to production socio-economic and organizational and technological systems. Such systems should include construction.

It is important to emphasize that long-term use of the concept of reliability in research and practical activities of enterprises, did not lead to a unified approach to quantification of this category, including with consideration of its application. Only the assessment of the technical reliability of machine systems and mechanisms has a whole set of standards that set requirements for the source information and determine the methods of mathematical calculations of the quantitative value of the "reliability" indicator. If we group methodological approaches to quantifying the "reliability" indicator in relation to systems in which human actions play an important role, it is easy to identify several of the most widely used tools, which include:

- the theory of probability [3];

- the theory of risk [4];

- methods of expert assessments [5];

- methods for predicting and preventing failures [6].

The application of risk theory to assess the reliability of organizational and technological solutions [7], including at industrial and energy enterprises does not provide a level of reliability, it is necessary when predicting the duration of construction and installation work. The study of failures, including in socio-technical systems [8], does not provide the required reliability in predicting the intensity of construction of buildings and structures. From the author's point of view, the methods of probability theory are most suitable for assessing the reliability of organizational and technological solutions in construction. These methods are widely used in calculating the quantitative value of organizational and technological reliability [9], including in the preparatory period [10], as well as organizational design and project management systems [11].

The purpose of the research is to propose a procedure for evaluating the organizational and technological reliability of a construction organization during contract bidding.

\section{Materials and Methods}


The paper uses methods of probability theory. The accumulated probability curve is constructed based on data obtained from design estimates and regulatory documentation.

\section{Results}

One of the main indicators of reliability of a construction organization is the duration of production of construction products, which determines the construction lines. The duration of construction production depends on the duration of individual stages of construction, the types of construction products produced, as well as the potential of the organizational, technological, technical and financial capabilities of the contractor. Therefore, when assessing the competitiveness of a construction company, the customer is interested in predicting the probability of completion of the construction project on time.

To determine the reliability of a construction organization, it is proposed to use information about the intensity of development of capital investments. This is due to the fact that the cost of work and the duration of individual construction stages are calculated based on specific organizational and technological solutions. Organizational and technological solutions, in turn, depend on the machines and mechanisms used, the types of technological processes, the volume of work and regional features of construction.

Thus, when choosing a construction company, the customer must assess the level of its organizational and technological reliability based on the intensity of capital investment development. This indicator allows you to assess how much the applicant can provide the maximum return on the construction equipment and workers used, reduce the cost of construction using modern construction materials and resource-saving technologies.

In previous works [12], it was shown that the intensity (or speed) of capital investment development is a probabilistic value and varies depending on the types of work performed. Therefore, it was proposed to use the capital investment development index as an indicator that characterizes the relative change in the actual development of capital investments from the standard or calculated value. Formula for calculating it:

$$
t=\frac{W_{f}}{W_{N}}
$$

Where $W_{f}$ is the value of the actual development of capital investments per unit of time;

$W_{N}$ - the amount of development of capital investments per unit of time, which can be determined on the basis of standards or can be proposed in the construction organization project.

Since the intensity (speed) of capital investment development is a probabilistic value, the capital investment development index is an uncertain value and its changes are subject to the law of normal distribution [13]:

$$
f(t)=\frac{1}{\sigma \sqrt{2 \pi}} e^{\frac{-\left(t-t_{c p}\right)^{2}}{2 \sigma^{2}}}
$$

Where $f(t)$ is the differential function of the normal distribution;

$\sigma-$ mean square deviation;

$t$ - the index of development of capital investments;

$t_{c p}$ - average value of the capital investment development index.

The integral function or distribution function is calculated using the formula: 


$$
F(t)=\frac{1}{\sigma \sqrt{2 \pi}} \int_{0}^{+\infty} e^{\frac{-\left(t-t_{c p}\right)^{2}}{2 \sigma^{2}}} d t
$$

Graphs of the integral and differential functions of the normal distribution of the capital investment development index are shown in figure 1.

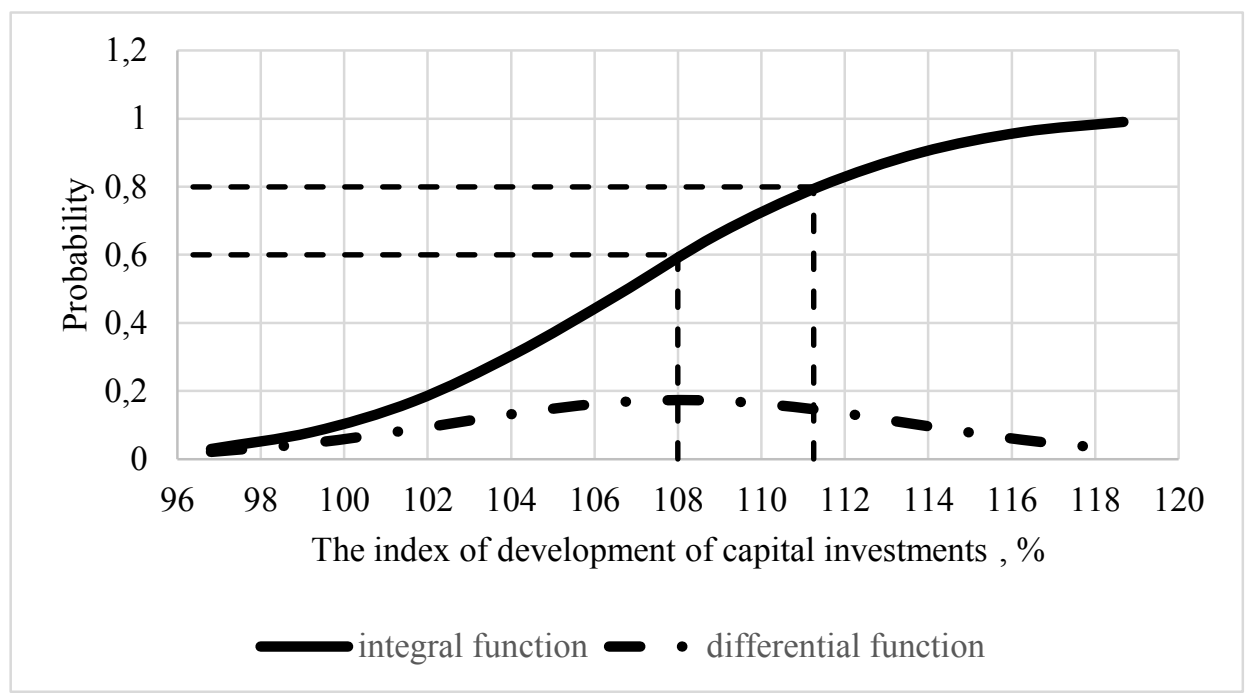

Fig. 1. Integral and differential functions of the law of normal distribution of the capital investment development index.

On the basis of the integral function, the probability of building an object on time with the specified values of the capital investment development index is calculated. Figure 1 shows that if the rate of development of capital investments exceeds the average value by no more than $8 \%$, the probability of construction of the object on time will be 0,6 . If the rate of development of capital investments exceeds the average (or standard) indicator by no more than $11,25 \%$, then the probability of building construction on time will be 0,8 .

A. A. Gusakov, the founder of system engineering in construction, believed that the probability of building a construction object on time should be in the range of $0.6-0.75$. Thus, if the value of the index of development of capital investments of a construction organization corresponds to a value less than 0.6 for the distribution function, then the organizational and technological reliability of the organization is low, if it is in the range from 0.6 to 0.8 - normal, above 0.8 - high.

Each construction and installation organization will have its own intensity of development of capital investments. It depends on the qualification of employees, the availability and use of a fleet of construction machines and mechanisms, construction production technologies, construction organization methods, etc. The index of capital investment development for the same organization may vary depending on the type and type of building being built.

To assess the organizational and technological reliability of a contractor, the most promising approach from the author's point of view is to build curves of accumulated probabilities. To do this, it is necessary to collect retrospective data on the contractor's performance of construction and installation works. And based on information about the volume of capital investment development for a certain period (1 day, week, 10 days, etc.), build curves of accumulated probabilities for various types of buildings and structures. Work logs and primary documents can be used as a source of information. These curves 
will show the reliability of the construction organization for construction on time with the specified estimated cost of the construction object.

To assess the organizational and technological reliability of bids, an organization that conducts auctions based on data for all similar objects builds an average curve of accumulated probabilities of capital investment development indices. The construction and installation organization participating in the auction is invited to provide information about the cost and timing of construction of five similar objects. According to formula 1, the average intensity of development of capital investments is calculated from the bidder's tender offer and the reliability of construction of the object on time is determined using the averaged curve of accumulated probabilities.

If data on development of capital investments on facilities analogues no, in this case, you can use the method of trial design and on the basis of design estimates of standard projects of buildings and structures, the integrated cost indexes of construction works, normative documents, (GEES, FER, TER, etc.), possibilities of the average contractor in the region to build the curves of the accumulated probabilities at the species and types of buildings and structures.

As an example, let's consider the construction of a simulation model of the probability of building a 9-storey brick house with an area of $12060 \mathrm{~m}^{2}$ on time.

In accordance with MDS 12-43.2008 and individual costs for construction and installation work, table 1 of the financing requirements for construction stages was compiled.

Table 1. Distribution of capital investments by stages of construction of a 9-storey brick building, thousand rubles

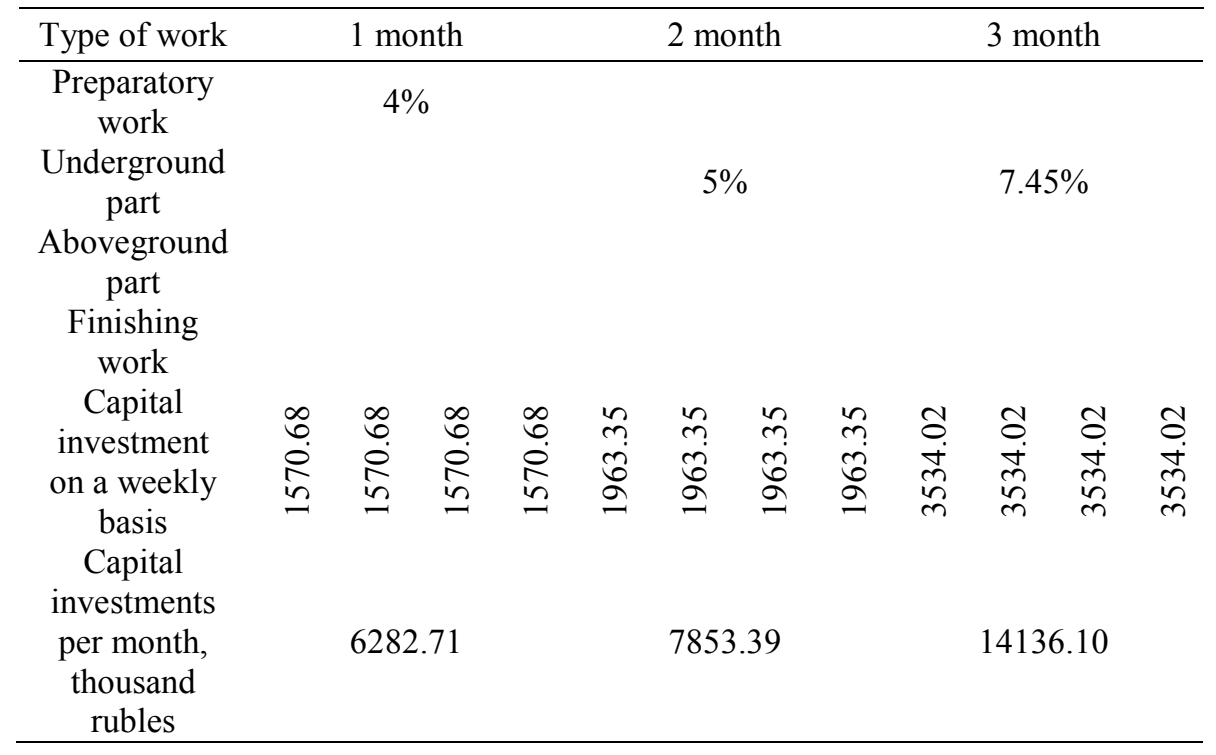

continuation of table 1

$\begin{array}{ccccc}\text { Type of work } & 4 \text { month } & \ldots & 11 \text { month } & 12 \text { month } \\ \begin{array}{c}\text { Preparatory work } \\ \text { Underground part }\end{array} & & & & \\ \begin{array}{l}\text { Aboveground part } \\ \text { Finishing work }\end{array} & 8 \% & \ldots & 8 \% & 8 \% \\ \end{array}$




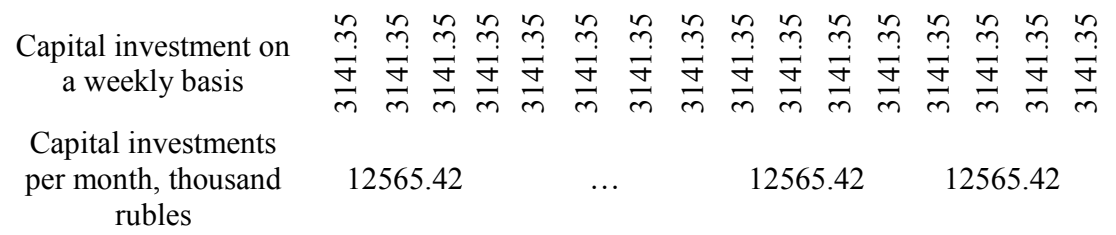

Using variant design, all possible alternative technologies for performing simple construction processes are formed, as well as possible solutions within each technology, which are determined by the potential of the available organizational and technological resources of an average contract construction organization in Moscow.

The variants of the monthly rate of development of capital investments obtained for each type of construction work are presented in table 2 .

Table 2. Development of capital investments in the construction of a 9-storey brick house, thousand rubles

\begin{tabular}{lccc}
\hline \multicolumn{4}{c}{ Alternative ways to develop capital investments } \\
\hline 2011 & 3651 & 3647 & 2113 \\
1974 & 3721 & 3784 & 1991 \\
2215 & 3725 & 3556 & 2176 \\
2054 & 3574 & 3634 & 2300 \\
2355 & 3655 & 3927 & 1871 \\
2080 & 3652 & 4021 & 1957 \\
2175 & 3863 & 3883 & 1936 \\
2146 & 3690 & 3657 & 2193 \\
2107 & 3722 & 3727 & 2085 \\
2089 & 3493 & 3878 & 2302 \\
2070 & 3682 & 4009 & 2143 \\
2087 & 3718 & 4211 & 2136 \\
2117 & 3925 & 4032 & 2099 \\
2076 & 3639 & 3903 & 2102 \\
2115 & 3457 & 4146 & 2156 \\
2132 & 3721 & 3943 & 2017 \\
2014 & 3547 & 3919 & 2053 \\
2302 & 3607 & 3720 & 2218 \\
2143 & 3719 & 3422 & 2335 \\
2019 & 3612 & 3489 & 2098 \\
2340 & 3440 & 3410 & 1944 \\
2095 & 3642 & 3968 & 2296 \\
2244 & 3532 & 4056 & 2229 \\
2159 & 3455 & 3861 & 2093 \\
3934 & 3648 & 3965 & 2132 \\
3674 & 3678 & 3854 & 2109 \\
3864 & 3503 & 3728 & 2107 \\
3651 & 3572 & 3760 & \\
\hline & & & \\
\hline
\end{tabular}

Formula 1 calculates the intensity of development of capital investments (table 3).

Table 3. Variant indices of development of capital investments in the construction of a 9-storey brick house 


\begin{tabular}{|c|c|c|c|}
\hline 102.43 & 105.29 & 103.19 & 107.64 \\
\hline 100.54 & 105.40 & 107.07 & 101.43 \\
\hline 112.82 & 101.13 & 100.62 & 110.85 \\
\hline 104.62 & 103.42 & 102.83 & 117.17 \\
\hline 119.95 & 103.33 & 111.12 & 95.31 \\
\hline 105.94 & 109.31 & 113.78 & 99.69 \\
\hline 110.78 & 104.41 & 109.87 & 98.62 \\
\hline 109.30 & 105.32 & 103.48 & 111.72 \\
\hline 107.32 & 98.84 & 105.46 & 106.21 \\
\hline 106.40 & 104.18 & 109.73 & 117.27 \\
\hline 105.43 & 105.21 & 113.44 & 109.17 \\
\hline 106.30 & 111.06 & 119.16 & 108.81 \\
\hline 107.83 & 102.97 & 114.09 & 106.93 \\
\hline 105.74 & 97.82 & 110.44 & 107.08 \\
\hline 107.72 & 105.29 & 117.32 & 109.83 \\
\hline 108.59 & 100.36 & 111.57 & 102.75 \\
\hline 102.58 & 102.06 & 110.89 & 104.58 \\
\hline 117.25 & 105.23 & 105.26 & 112.99 \\
\hline 109.15 & 102.20 & 96.83 & 118.95 \\
\hline 102.83 & 97.34 & 98.73 & 106.88 \\
\hline 119.18 & 103.05 & 96.49 & 99.03 \\
\hline 106.71 & 99.94 & 112.28 & 116.96 \\
\hline 114.29 & 97.76 & 114.77 & 113.55 \\
\hline 109.97 & 103.22 & 109.25 & 106.62 \\
\hline 111.32 & 104.07 & 112.20 & 108.61 \\
\hline 103.96 & 99.12 & 109.05 & 107.44 \\
\hline 109.34 & 101.07 & 105.49 & 107.34 \\
\hline 103.31 & 105.21 & 106.39 & \\
\hline
\end{tabular}

Based on the information received, a statistical series is compiled (table 4).

Table 4.Statistical series of variant indices of capital investment development during the construction of a 9-storey brick house

\begin{tabular}{|c|c|c|c|c|c|c|c|c|c|c|}
\hline Interval, \% & $\begin{array}{l}95.31 \\
- \\
97.77 \\
\end{array}$ & $\begin{array}{l}97.77 \\
- \\
100.23 \\
\end{array}$ & $\begin{array}{l}100.23 \\
- \\
102.69 \\
\end{array}$ & $\begin{array}{l}102.69 \\
- \\
105.15 \\
\end{array}$ & $\begin{array}{l}105.15 \\
- \\
107.61 \\
\end{array}$ & $\begin{array}{l}107.61 \\
- \\
110.07 \\
\end{array}$ & $\begin{array}{l}110.07 \\
- \\
112.53 \\
\end{array}$ & $\begin{array}{l}112.53 \\
- \\
114.99 \\
\end{array}$ & $\begin{array}{l}114.99 \\
- \\
117.45 \\
\end{array}$ & $\begin{array}{l}117.45 \\
- \\
119.95 \\
\end{array}$ \\
\hline Frequency & 5 & 8 & 10 & 17 & 26 & 17 & 11 & 8 & 5 & 4 \\
\hline Probability & $\begin{array}{l}0.0 \\
5\end{array}$ & 0.07 & 0.09 & 0.15 & 0.23 & 0.15 & 0.10 & 0.07 & 0.05 & 0.04 \\
\hline $\begin{array}{l}\text { The } \\
\text { cumulative } \\
\text { probability }\end{array}$ & $\begin{array}{l}0.0 \\
5\end{array}$ & 0.12 & 0.21 & 0.36 & 0.59 & 0.75 & 0.85 & 0.92 & 0.96 & 1.00 \\
\hline \multicolumn{3}{|c|}{ Average, $t(\%)$} & \multicolumn{8}{|c|}{106.87} \\
\hline \multicolumn{3}{|c|}{$\begin{array}{l}\text { Meansquaredeviation, } \\
(\%)\end{array}$} & 5.31 & & & & & & & \\
\hline \multicolumn{3}{|c|}{ Coefficient of variation, $V$} & 0.41 & & & & & & & \\
\hline
\end{tabular}

A curve and a polygon of accumulated probabilities are plotted based on the statistical series data (Fig. 2). 


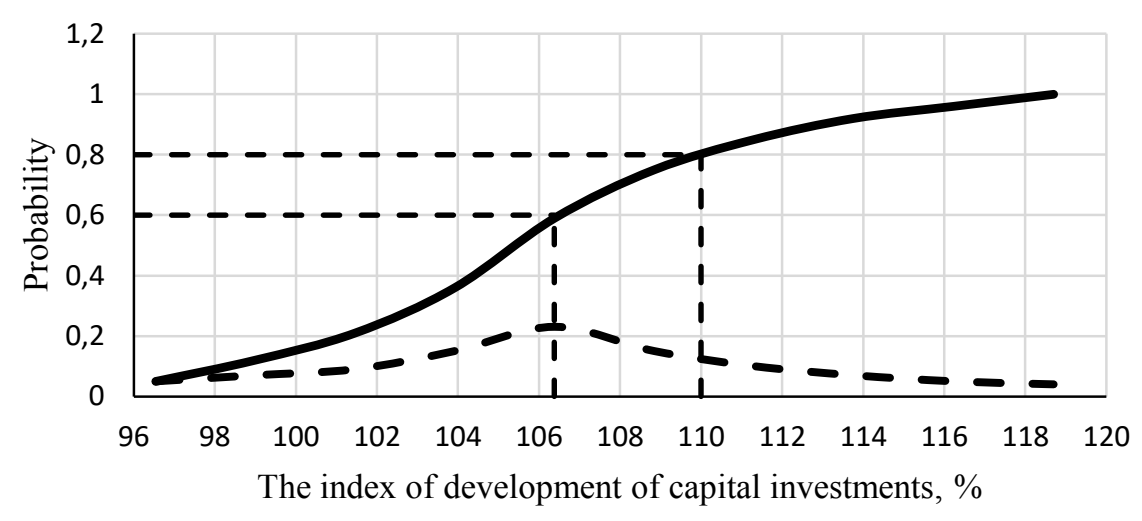

the curve of accumulated probability - the polygon distribution

Fig. 2. Polygon and curve of accumulated probabilities of capital investment development indices during the construction of a 9-storey brick building

Figure 2 shows that the bidder must offer the speed of development of capital investments at least $6-10 \%$ higher than the Directive value, in order to increase the organizational and technological reliability of the construction of a 9-storey brick building on time.

The proposed mechanism makes it possible to assess the reliability of contractors when performing construction and installation works and their tender offers.

\section{Conclusions}

Using retrospective data on the speed of development of capital investments for similar objects or using variant design of the construction process, curves of accumulated probabilities of indices of development of capital investments are constructed, on the basis of which the organizational and technological reliability of the contract bidder is determined.The proposed assessment of the reliability of the construction organization allows the customer (investor) to choose a reliable partner - contractor that best meets its potential and requirements, and the contractor has an incentive to increase labor productivity and improve the quality of construction and installation work.

\section{References}

1. A.A. Gusakov, Organizational and technological reliability of construction production (Moscow, Stroyizdat, 1974).

2. A.V. Ginzburg, Organizational and technological reliability of construction systems MGSU Bulletin, 4, 251-255 (2010).

3. V.N. Kabanov, Organizational and technological reliability of the construction process, Civil engineering magazine, 1 (77), 59-67 (2018).

4. L.D. Gitelman, L.M. Gitelman and M.V. Kozhevnikov, A methodological framework for organizational risk management in energy companies, International Journal of Safety and Security Engineering, 7 (1), $41-51$ (2017) 
5. P. Malik and P. Garg, Vikalpa, Psychometric Testing of the Resilience at Work Scale Using Indian Sample, 2, 77-91 (2018).

6. Z. Zheng and J. Tian, Proceedings of the 26th European Safety and Reliability Conference ESREL, Application of FRAM to risk assessment in manufacturing process, 3722017

7. J. Pence, Y. Sun, X. Zhu, (...),C. Ostroff and E. Kee, International Topical Meeting on Probabilistic Safety Assessment and Analysis, PSA Data-theoretic methodology and computational platform for the quantification of organizational mechanisms in probabilistic risk assessment, pp 1294-1300 (2017).

8. P. McFarlane, Failure in complex socio-technical security systems: Why do they repeat given that, in theory, they create opportunities for active learning? Security Risks: Assessment, Management and Current Challenges (Book Chapter), pp 131-146 (2017).

9. A. Ginzburg, A. Bolotova, A. Dolganov, I. Vedyakov and M. Vaynshteyn, Organizational-Technological Reliability of Monolithic Construction, Advances in Intelligent Systems and Computing, pp. 1160-1167 (2018).

10. V. Chulkov, A. Kiselev, G. Maloyan and A. Efimenko, Organizational-technological solutions, risks and reliability of the preparatory period of the renovation of territories, Advances in Intelligent Systems and Computing, pp. 367-375 (2017).

11. D. Topchiy and A. Tokarskiy, Designing of structural and functional organizational systems, formed during the re-profiling of industrial facilities, IOP Conference Series: Materials Science and Engineering (2018).

12. E.V. Mikhaylova, Probabilistic estimation of the duration of construction of buildings and structures, IOP Conference Series: Materials Science and Engineering (CATPID 2019). doi:10.1088/1757-899X/698/5/055009

13. V.N. Kabanov and E.V. Mikhaylova, Determination of organizational and technological reliability of a construction organization, Construction economics, 4 (17), 67-78 (2012). 